\title{
On the sesquipersulphate of mercury
}

\section{Lieut W.T. Hopkins}

To cite this article: Lieut W.T. Hopkins (1830) On the sesquipersulphate of mercury, Philosophical Magazine Series 2, 8:48, 463-464, DOI: 10.1080/14786443008675507

To link to this article: http://dx.doi.org/10.1080/14786443008675507

$$
\text { 曲 Published online: 14 Jul } 2009 .
$$

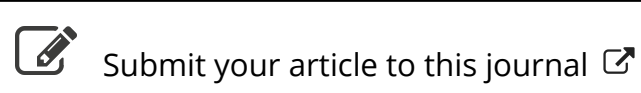

LII Article views: 1

Q View related articles $\asymp$ 
-A series, consisting of more than 300 Rock specimens, illustrative of the Geology of the Northern and Central part of Cornwall. By Henry S. Boase, M.D.-Three additional specimens from the neighbourhood of Liskeard. By the Rev. Canon Rogers.-A series of specimens in illustration of the Geology of Dartmoor, with a memoir. By John Prideaux, Esq. of Plymouth.-A series of Rocks and Organic Remains from Yorkshire. By the Yorkshire Philosophical Society.-Specimens from the Manganese Beds near Tavistock, and some specimens of Greenstone Slate; also, specimens of Schorl Rock from Park Wood. By Mr. W. J. Henwood.-A series of specimens from the Garth Mine. By Joseph Carne, Esq.-Quarterly Mining Review, Nos. 1, 2, 3. By Henry English, Esq. the editor.-Geological Notes. By the author, Henry Thomas De la Beche, Esq. F.R.S. \&c.-Asiatic Researches. By the Asiatic Society.

Officers and Council for the present year :-President: Davies Gilbert, Esq. M.P. P.R.S., \&c. \&c.-Vice-Presidents : The Earl of Falmouth; Sir Rose Price, Bart.; John Hawkins, Esq. ; Francis Hearle Rodd, Esq.-Secretary: E. C. Giddy, Esq.-Treasurer: Joseph Carne, Esq.-Librarian: Thomas Hingston, M.D.-Assistant Secretary: R. Moyle, Esq.-Council: Doctor Boase ; Wm. Cornish, Esq. ; Richard Davey, Esq.; Day P. Le Grice, Esq.; H. M. Grylls, Esq.; Alfred Fox, Esq.; James Plomer, Esq.; Wm. Reynolds, Esq.; Wm. M. Tweedy, Esq.; Wm. Williams, Esq.

New Members : Edward Collins, Esq. Truthan ; the Rev. Michael Noel Peters, Penzance; and Charles Fox, Esq. Perran Wharf.

LXXI. Intelligence and Miscellaneous Articles.

\section{oN THE SESQUipersulphate OF MERCURY. BY LIEUT. W. T. HOPKINS, UNITED STATES.}

"Having had occasion, lately, to pour strong nitric acid on the yellow neutral persulphate of mercury, known as the 'turpeth mineral,' 1 observed that a portion of the salt disappeared, while the remainder was converted into a white powder. This substance was readily reconverted by water into the yellow salt. I succeeded however in edulcorating a portion of it without change ; and upon boiling thirty grains of it with nitrate of baryta, digesting afterward with nitric acid, (to remove a portion of peroxide of mercury which was deposited,) washing, drying, and weighing, I obtained 19 grains of sulphate of baryta. Now 19 grains of sulphate of baryta contain $6.44 \mathrm{grs}$. of sulphuric acid, and the white powder submitted to experiment consisted of sulphuric acid, 6.44 grs. + peroxide of mercury, 23.56 grs. $=30$. We have therefore the proportion

$$
23 \cdot 56: 6 \cdot 44:: 216: 59 \cdot 04
$$

where 216 represents the atom of peroxide of mercury, and 59.04 the quantity of sulphuric acid that would combine with it to produce the compound under examination. If the numbers I had obtained had been 6.48 and 23.52 , the proportion would have been

$$
23 \cdot 52: 6 \cdot 48:: 216: 60
$$


and this last term would precisely represent $1 \frac{1}{2}$ atom of sulphuric acid. The hastiness of my experiment could account for a much greater discrepancy.

This sesquisulphate has no very interesting properties. It appears to be insoluble, but is easily decomposed by cold water. It is usually said that the action of water upon the white bipersulphate of mercury consists in the resolution of it into the yellow, insoluble, neutral sulphate, and a soluble supersulphate. Yet upon evaporating the liquor thus obtained, $I$ observed the deposition of a white substance resembling in its external characters the bipersulphate; while the supernatant liquid had those of free sulphuric acid."-Silliman's Journal, vol. xviii. p. 364.

\section{ON CHLORIDE OF SILVER. BY M. CAVALIER.}

The colour produced in chloride of silver by the action of light has long been known, and a similar change is apparently produced by some chemical reagents, but whether the alterations are identical is a question which $M$. Cavalier says he does not pretend to decide; he then states a method by which the violet chloride of silver may be procured without the agency of light : Dissolve some recently prepared and perfectly white chloride of silver in ammonia, and pass a current of chlorine gas through it, and the same phænomena as occur when the gas is passed through mere solution of ammonia will be presented; such as slight detonation on the arrival of each bubble, abundant white vapours, increase of temperature, and the disengagement of azotic gas, \&c. Afterwards the solution becomes turbid, and soon a grayish precipitate is observed, and at length it assumes a well marked violet colour; this colour occurs when the ammonia is completely decomposed by the chlorine.

What is the nature of this new substance? Is it a smaller or greater quantity of chlorine which has modified the properties of the chloride, or is it identical with the white chloride; and is the colour acquired merely by a different molecular arrangement ?

The following experiments are in favour of the latter opinion.

If the violet chloride be dissolved in ammonia, nitric acid precipitates it white. Take 20 grains of violet and 20 grains of white chloride, put each into a glass and with them diluted sulphuric acid and a piece of zinc, stirring the chloride with the latter so as to keep it suspended; the chlorides are both decomposed by the hydrogen evolved and metallic silver is obtained, and from each chloride the same quantity, viz. 15 grains.

According to these experiments, the new substance cannot be regarded either as a subchloride or a deutochloride ; every circumstance seems to prove that the colour is produced merely by a different molecular arrangement. In this case it remains to be explained what is the body which forces the chloride to acquire a different physical property. The heat produced during the operation has certainly nothing to do with it, for the experiment succeeds equally when the vessel is placed in a freezing mixture.-Journal de Pharmacie, xvi. 552. 